\title{
Primera etapa de la colonización fenicia
}

\author{
YU B. TSIRKIM*
}

En la historia de la colonización fenicia los más obscuros y los más discutibles son los problemas de su etapa inicial. La tradición antigua fija su comienzo hacia finales del segundo milenio a. C., datación aceptada por la historiografía europea del siglo XIX. Sin embargo, a finales de ese siglo, J. Beloch, siguiendo el generalizado curso hipercrítico de la historiografía (también, quizá, debido a sus aficiones políticas) recusó categóricamente tales dataciones antiguas considerando la colonización fenicia contemporánea de la colonización griega, e incluso en sus etapas avanzadas ${ }^{1}$. Aunque las fechas de $\mathrm{J}$. Beloch parecen hoy demasiado recientes, la mayoría de los eruditos atribuye el inicio de la actividad colonial fenicia a un tiempo no más temprano que el siglo IX a. C. Con todo, hay un grupo de especialistas que sigue la opinión tradicional ${ }^{2}$.

Los argumentos principales de los adversarios de las fechas antiguas se reducen prácticamente a las ideas comunes acerca del caos producido en el Mediterráneo Oriental a causa de los movimientos étnicos y de la disolución o el debilitamiento de los estados dirigentes, a la ausencia de unas pruebas arqueológicas de la colonización temprana (frente a la presencia

* Centro de Estudios Históricos de Leningrado.

J. BELOCH: "Die Phoenikier an Aegeischen Meer", en Rheinisches Museum, 49 (1894), págs. 111-132.

2 Por ejemplo: I. Sch. SchifmanN: Vozniknoveny Karfagenskoy derjavi, Moscú-Leningrado, 1963, 6-37; H. J. KATZENSTEIN: History of Tyre, Jerusalèn, 1973, 75; O. NEGBI: Biblical Archaeology today, Jerusalén, 1985, 222; R. STIEGLITZ: The Geopolitics of the Phoenician Littoral in the Early Iron Age", BASOR, 279 (1990), II; W. Huss: Die Karthager, München, 1990, 5. Hay investigadores de una opinión intermedia. Por ejemplo, C.G. WAGNER acepta las fechas tradicionales, pero considera que tienen relación con unos primeros contactos esporádicos de los fenicios con el Mediterráneo Occidental: E.C.G. WAGNER, Fenicios y cartagineses en la Península Ibérica, Madrid, 1983. 22; Idem, "Gadir y losmás antiguos asentamientos fenicios al este del Estrecho", Actas del Congreso Internacional el Estrecho Gibraltar, Ceuta, 1987, 420-421. 
de pruebas para los siglos IX-VII a. C.) y a la aparente inseguridad de la tradición antigua ${ }^{3}$.

Acerca de estos argumentos hay que hacer notar, en primer lugar, que las ideas sobre el caos del Mediterráneo son exageradas. La datación de los estados de Grecia micénica que antes dominaban la navegación y el comercio mediterraneo pudo ser incluso favorable a los fenicios ${ }^{4}$. Es poco probable que la piratería pudiera reprimir a los marineros; la piratería es propia de la Antigüedad en general: de piratas habla Homero, contra piratas luchaban César y Pompeyo, y los propios fenicios no desdeñaban esta profesión; de modo que los piratas creaban dificultades pero jamás eran obstáculos insalvables para el comercio marítimo y la colonización. El cuerpo de las fuentes arqueológicas, a diferencia de la tradición escrita, está abierto, y nadie puede negar la posibilidad de que, como ya ha ocurrido, nuevos descubrimientos confirmen noticias de la tradición antes considerada como increíbles ${ }^{5}$.

El análisis de la tradición realizado por G. Bunnens, a pesar de ser cuidado, no siempre parece convincente, sobre todo respecto a la etapa inicial de la colonización.

Tucídides (I, 8) menciona a fenicios y carios a la par, al referirse a los bandidos que se establecieron en las islas del mar Egeo. Pero después, el historiador habla sólo de los carios: de las excavaciones de sus tumbas por los atenienses en el tiempo de las guerras del Peloponeso; e incluso de mucho antes, cuando la potencia marítima de Minos logró expulsar a los carios de las islas. De su estancia anterior en las islas del Egeo, de poder de Minos y de la expulsión llevada a cabo por él, trata también la leyenda de Creta que conservó Heródoto $(I, 171)$, y el recuerdo de la dominación del mar por los carios llego a la cronografía cristiana (Eusebio) ${ }^{6}$. Se puede estimar diferentemente esta noticia y tratar de establecer su base histórica (si existe), pero está claro que la noticia sobre la expulsión

3 Por ejemplo: J.D. MuLY, “Phoenicia and Phoenicians», Biblical Archaecology today, 179; G. Bunnens, L'expansion phénifcienne en Medierranée, Bruselas-Rome, 1979; M.E. AuBEt SEMMLER, "Los fenicios en España: estado de la cuestión y perspectivas", en: Los fenicios en la Peninsula lbérica. Sabadell, 1986, págs. 11-12.

4 Cf. W.F. AlbRIGHT, "Syria. The Philistines and Palestine", en: CAH, V II, 1966, p. 35; A. VAN DEN BRANDEN, “La Fenicia nel secoli XII-X prima dell'era volgare”, en: Biblia e Oriente, 17, 1975, pp. $145-170$.

5 Cf. V.G. BorujoVICH, "Nauchnoe i literaturnoe znachenie truda Gerodota", en: Gerooot, Historiya. Moscú, 1972, p. 485; P.J. RHodEs, "In Defense of the Greek Historians", en: Greece and Rome, V. 41,2 (1994), p. 161.

6 A. Kammenhuber, Karer, Karia, en: Kleine Pauly. Bd. Ill. 1979, Sp. 119; G. Thomson, Frühgeschicte Griechenlands und der Ägäis. Berlin, 1960, S. 130-136, 136-137. 
de los carios no se puede atribuir a los fenicios; es imposible también afirmar la simultaneidad de la estancia de unos y otros en las islas. Heródoto (II, 44; VI, 47) y Pausanias (II, 25, 12) informan sobre la fundación por los fenicios del templo de Heracles en Tasos y sobre su explotación de los yacimientos de oro situados entre Ainyra y Kinyra. Estos nombres, por lo menos Kinyra, pasan por semitas ${ }^{7}$. Pausanias recalca que el Heracles de Tasos es la misma divinidad que se venera en Tiro, y que sólo más tarde los helenos de esa isla han empezado a venerar al Heracles griego. La investigación del culto de Heracles en Tasos ha revelado que se trata del Melqart tirio ${ }^{8}$. D. Van Berchem supuso que los fenicios habian llegado a Tasos a través de Cos, Eritras y Lemnos ${ }^{9}$. Esta suposición se confirma por el carácter y dirección de las relaciones comerciales del Tasos prehelénico, particularmente con Lemnos, lugar de mercado fenicio según Homero (IL. XXIII, 745) ${ }^{10}$. La ruta hacia Tasos pasaba por Rodas, donde, según Diodoro $(\mathrm{V}, 58,2)$, también existieron establecimientos fenicios, cuya fundación atribuye él a Cadmo. Los historiadores rodios hablan del jefe de los fenicios de esta isla, Falas (Ath. VIII, 360 e).

En el sur del Egeo los fenicios, según Esteban de Bizancio (v. Miাlos), fundaron en Melos la ciudad homónima, y también se instala en Tera (Her. IV, 147). Heródoto $(I, 105)$ atribuye a los fenicios la fundación del santuario de Citera. según Pausanias (III, 23, 1), este santuario es el más antiguo de Afrodita en Grecia, y allí la diosa se presenta armada. Poco concuerda eso con la diosa griega del amor, pero armada, a modo de Minerva, aparece Astarté la diosa del amor, con quien habitualmente se identifica a Afrodita en las monedas de la Sexi fenicia de Hispania "1. F.G. Movers señalaba aún que, Rodas, Tera, Melos y Citera están situadas en la ruta hacia el Oeste ${ }^{12}$.

Tucídides (VI, 2, 6) dice, que, antes de la llegada de los griegos a Sicilia, en los cabos y en los islotes cercanos habitaban los fenicios. Los lingüistas identifican como semitas topónimos tales como Tapso, Pajino, Tamaricio, Makara, Mazares ${ }^{13}$. Todos ellos están en las costas meridionales y orientales de Sicilia, pudiendo haber sido visitados más temprano por

\footnotetext{
D. Van Berchem, Sanctuaires d' Hercule-Melqart, en: Syria, t. 46 (1967), p. 10, n. 2 ; F. SaLviat, "Lions d'ivore à Thasos", en: $B C H, 86$ (1962), pp. 108-109, n. 7.

a D. Van Berchem, Op. cit., pp. 88-107; B. Berouist, Herakles on Thasos. Upsala, 1973, p. 35; W. GÜNTER, “Thasos”, en: Griechenland. Lexikon der historischen Städten, Munich, 1989, 658. Cf. M. Gras, P. Rouillatid, J. Teixidor, L'univers phenicien. París, 1989, p. 50.

9 D. VAN BERCHEN, Op. cit, p. 107-108.

10 A.J. Graham, "The Foudantion of Thasos", en: ABSA, 23 (1978), pp. 90-91.

11 A. Garcia Y BELLIDO, Les religions orientales dans /' Espagne romaine. Leiden, 1967, p. 13.

12 F.G.Movers, Die Phönizier. Berlín, 1850, S. 256.

13 I.SCH. SCHIFMANN, Op. cit., p. 27-29; J. BÉRARD, La colonisation grecque de l'italie méridionale et de la Sicile dans l'antiquité. Paris, 1953, pp. 69-70; H. PHILIPO, "Tamariscium sive Palma»,
} 
los fenicios, a juzgar por el hallazgo de una estatuilla fenicia de los siglos XIV-XIII a. C. en el mar, cerca del litoral meridional de Sicilia ${ }^{14}$.

Después de Sicilia, se abrieron a los fenicios Hispania y Africa. Estrabón (III, 2, 14; I, 2, 3), Diodoro (V, 20; 35) y Veleyo Patérculo (I, 2, 3-4) ligan las fundaciones de las colonias a estas regiones. Hispania y la costa opuesta de Africa eran las tierras más occidentales de la colonización fenicia. Aquí el centro más importante llegó a ser Gades, que, según Estrabón (III, 5, 5), fue fundado después de dos tentativas desgraciadas, explicables posiblemene por la hostilidad de los aborígenes. A esos aludirá también el nombre de la ciudad-Gadir (el lugar cerrado). Tal vez entre las dos tentativas fallidas de instalarse en Hispania se establecieron los tirios en Lixus, en la costa africana ${ }^{15}$. En todo caso, Plinio $(X I X, 53)$ dice que el santuario lixita de Hércules, el Melqart fenicio era mas antiguo que el gaditano. Según Patérculo, después de pocos años los fenicios fundaron Utica.

Así pues, se muestran dos rutas de la expansión fenicia colonial una, de Rodas a lo largo del litoral occidental de Asia Menor: hasta Tasos; otra, de la misma Rodas, a lo largo del borde meridional del Egeo, hasta Sicilia, Africa e Hispania. Esas rutas están en función, respectivamente de las minas de oro de Tasos y del argentífero hispano ${ }^{16}$. El objetivo esencial de los puntos intermedios parece haber sido el de asegurar estos caminos.

¿Cuándo se han originado esas rutas? Heródoto, que en este caso se apoya en la tradición del pais establece la llegada de los fenicios a Tera ocho generaciones antes que la de los lacios (IV) (147). la duración de una generación en Heródoto bascula entre treinta y cuarenta años, pero, en general, tres generaciones comprenden cerca de cien años ${ }^{17}$. Asi pues, los fenicios, según este autor, han llegado entre doscientos cuarenta y trescientos veinte años antes que los laconios. Los laconios emigraron a Tera, según parece, a comienzos del siglo VIII a. C. ${ }^{18}$; por eso la llegada de los fenicios hay que atribuirla a la primera mitad del siglo $\mathrm{XI} \circ \mathrm{a}$

en RE. SUpl. A2; K. ZIEGLER, "Sicilia", en RE, II, A2, 2489; idem, "Thapsos", en: RE, VA2, 1281. ahora parecen descubrirse las huellas de la presencia fenicia en esta región: $V$. TUSA. "La presenza fenicio-punica in Sicilia", en: P"honizier im Westen. Mainz am Rhein, 1982, p. 97.

14 D. HARDEN, The Phoenicians. Harmondsworth, 1971, p. 56, pate 93; A. PARROT, M. С HÉHAB, S. Moscati, Les Phéniciens. Paris, 1975, pp. 193-194, fig. 211.

15 I.Sch. Schifmann, Op. cit., p. 23-25; A. Schulten, Tartesos. Hamburgo 1950, S. 34-35.

16 CF. J. Latacz, "Die Phönizier bei Homer", en: Die Phönizier in Zeizalter Homers. Mainz, 1990, S. 12.

17 R. BALL, "Generation Dating in Herodotos", en: Classical Quarterly, 29 (1979), p. 281; S. YA LuRIÉ, Gerodot. Moscú-Leningrado 1947, p. III; W.W. HAW, J. WELLS, A Commentary o on Herodotos, t. I., Oxford, 1954, p. 439.

${ }_{18}$ L.H. JefFreY, Archaic Greece. Londres 1976, p. 185. 
finales del siglo XII a. C. Marinatos atribuye la conquista laconia de Tera a un tiempo no anterior al 700 a. C., pero también fecha la llegada de los fenicios a finales de la época micénica o en los inicios de la protogeométrica ${ }^{19}$.

Tucidides (VI, 112) pone en boca de los melios la afirmación que su comunidad existía desde hacia setecientos años. Es conocido que Tucídides escribía los discursos tal y como podrían ser pronunciados en la realidad, por lo que no cabe dudar de la afirmación por parte de los melios de la antigüedad de la ciudad. Puesto que el discurso fue pronunciado en el 416 a. C., el nacimiento de la comunidad, según los melios, se fecharía en el 1116 a. C. Sin duda el setecientos es un número redondo, que no se puede entender literalmente, pero el que los melios atribuyeran los inicios de su historia a los finales del siglo XII a. C. es muy probable. Puesto que los fundadores de la ciudad fueron, según Esteban de Bizancio, los fenicios, se puede decir que el establecimiento de los fenicios en Melos también se fecha a finales del siglo XII a. C.

Los orígenes de los puntos de apoyo fenicios en el Occidente extremo los fechan Mela (III, 46) y Veleyo Patérculo (1, 2, 3). Mela pretende que existía el templo gaditano desde los tiempos de la guerra de Troya. Conforme a Patérculo, Gades había sido fundado por la flota tiria, que entonces era la más poderosa en el mundo, ochenta años después de la caída de Troya, es decir en el 1105 a. C. Estas fechas se confirman por fuentes independientes. Patérculo menciona que Utica fue fundada un poco más tarde que Gades $(I, 2,4)$, y Plinio (XVI, 216) señala que el templo uticense fundado a la vez que la ciudad tenía mil ciento setenta y ocho años de existencia. La Naturalis Historia fue terminada en el 77 d. C. ${ }^{20}$; se ignora cuando fue escrito este fragmento, pero, en cualquier caso, esta noticia data la fundación de la ciudad y del templo a finales del siglo XII a. C. Citando unas "Historias fenicias" el Pseudo-Aristóteles (de mirab. ausc. 134) dice que Utica fue construida doscientos ochenta y siete años antes que Cartago. Aceptando las fechas diferentes de la fundación de Cartago, resulta para Utica el 1112, el 1110 o el 1104 a. C., lo que se corresponde con las fechas de Plinio y Veleyo Patérculo.

De esta manera, todos los indicios cronológicos, independientes unos de otros, que se cruzan y que no están ligados a la mitología, nos dan unas fechas próximas, que entran en el último cuarto del siglo XII, o tal

1y S. MARINATOS, "Ethnic problems raised by recent discoveries en Thera", en: Bronze Migrations in the Aegean. Londres, 1973, p. 200.

20 Istoriya rimscoy literatury, t. II. Moscú, 1962, p. 134; K. SallmanN, “Plinius", en: Kleine Pauly, 4 (1979), p. 932. 
vez, en el primer cuarto del siglo $\mathrm{Xl}$ a. C.; configurando un cuadro no contradictorio de la colonización fenicia temprana.

Todas las noticias sobre esta temprana actividad fenicia en el Mediterráneo y el Egeo se pueden dividir en dos grupos. El primero incluye las noticias ligadas a los templos y oráculos. A los cuentos y noticias acerca de los templos de Tasos, Citera, Gades, Lixus y Utica, hay que añadir el relato de Estrabón (III, 5, 5) sobre la fundación de Gades conforme a la orden del oráculo de Melqart. Los templos poseían vastos conocimientos sobre el origen y la historia de los santuarios. Heródoto (II, 44) transmite la noticia de los sacerdotes tirios de Heracles-Melqart, de que su templo había sido erigido dos mil trescientos años antes de la fundación de Tiro, es decir en el siglo XXVIII a. C. Estos datos se confirman por las cerámicas tirias, cuyas muestras más antiguas se remontan precisamente a este siglo. Ello permite creer en la exactitud de los cálculos cronológicos de los sacerdotes tirios ${ }^{21}$, lo que posibilita, a su vez, el tratar con más confianza otras noticias que se remontan a las tradiciones de los templos.

Heródoto afirma que los templos del Heracles tirio y tasio los ha visitado él mismo, de modo que su transmisión de la tradición del templo es inmediata. Tal vez se puede decir también algo similar sobre Mela, que habia nacido en Tingentera, cerca de Gades. En ese tiempo el templo gaditano era muy conocido y visitado por muchos romanos, de modo que los relatos ligados a él podrían haber sido oídos por el futuro geógrafo en su infancia, aunque no queda excluido, claro está, que unas primeras impresiones hispanas pudiesen haber sido completadas por informaciones de otras fuentes, entre ellas el cartaginés Hannon ${ }^{22}$.

Como una de las fuentes del libro tercero de Estrabón es considerado Posidonido ${ }^{23}$. Además, el propio Estrabón, precisamente en el relato sobre Gades, menciona a Artemidoro. Uno y otro, como afirma Estrabón (e.g. III, I, 4-5), estuvieron en Hispania, incluido Gades y su área. Al describir el Herakleion gaditano, Estrabón (III, 5, 7) cita a Polibio. Por lo visto, de esos escritores recibió el geógrafo las informaciones sobre la fundación de Gades, siendo su fuente última el relato de los gaditanos mismos, como claramente dice Estrabón (III, 5, 5).

2s M. BIKAl, The pottery of Tyre. Warmington, 1978, p. 72; M. GRAS, P. ROUILLARD, J. TEIXIDOR, Op. cit., p. 46; C. Baurian, C. Bonnet, Les Pheniciens. París, 1992, p. 59.

22 Istoriya rimscoy literatury, t. II, pp. 126-128.

23 G. BunNens, Op. cit., p. 193. 
Más complicado resulta establecer las fuentes de Plinio. Hablando sobre el templo de Utica, menciona la presencia de unas vigas de cedro de Numidia que permanecian allá desde la fundación del templo, simultánea de la de la ciudad. En las religiones semitas occidentales los restos del edificio original jugaban un gran papel. En relación con esto puede recordarse el Muro de las Lamentaciones del judaísmo. Y, en el templo gaditano, según Silio Itálico (III, 17-20), las vigas de madera no habían cambiado desde la fundación. Por eso no cabe dudar en resumidas cuentas de que la tradición del templo uticense este fundada en la noticia pliniana. En relación con el santuario lixita Plinio utiliza la expresión "ut ferunt"; pero ¿quiénes "ferunt"?. Tales hombres pudieron ser los sacerdotes del templo de Lixus.

La mayoría de los templos referidos son de Melqart (Heracles, Hércules), lo que no debe sorprender. Melqart el rey de la ciudad, el dueño de Tiro, era su protector ${ }^{24}$, la personificación de todo lo valioso y deseado para ella ${ }^{25}$. Es natural que sea también el jefe de la colonización. En una inscripción bilingüe del Malta (KAl 47) se nombra a este dios, en la parte fenicia como Señor de Tiro (Ba'al Sor), y en la griega como archegétes. En la mitología griega el papel archegétes-jefe lo desempeñaba Apolo. Así lo llaman Tucídides $(\mathrm{VI}, 3)$ y Pindaro (Pyth. $\mathrm{V}, 60-61)$ en relación con la fundación de Naxos y Cirene. Elio Arístides $(O r .27,5)$ argumenta sobre la diferencia entre las funciones de Apolo como exegétes y como archegétes: en el primer caso envía a otros a fundar nuevas ciudades; en el segundo, él mismo es oikistés directo ${ }^{26}$. Esto último seria Melqart de la serie de las colonias fenicias. Semejante papel aparece particularmente acentuado en Gades, ya que la ciudad misma fue fundada conforme a la orden del dios, y después Melqart profetizaba en el templo gaditano. Las campañas de Melqart (Sal. Jug. 18) fueron consideradas como la prehistoria mítica de la colonización; por eso es natural que en muchas colonias existieran santuarios de este dios y relatos sobre sus acciones.

Es necesario mencionar en la investigación actual la vasta difusión de la opinión de que el culto a Melqart surgió o, en todo caso, tomó forma definitiva, sólo en el siglo $X$ a. C. en el reinado de Hiram ${ }^{27}$. Tal opinión

24 K. Preisendanz, "Melkart", en: RE, SptBd. III, Sp. 293.

25 E. LesLIE, Old Testament Religion in the Ganaanite Background. New York-Chicago, 1936, p. 24.

26 M. LOMBARDO, "Le concenzioni degli antichi sul ruolo degli oracoli nella colonizzazione greca", en: Annali della Scuola normale superiore di Pisa, classe di lettere e filosofia, v. II, I, 1972, p. $69-70$.

27 S. Moscatl, “Melqart e i Fenici», en: RSF, XVI,2 (1988), pp. 253-256; R. DU MESNIL DU Buisson, Nouvelles études sur les dieux et les mythes de Canaan. Leiden, 1973, p. 44. 
está motivada por la noticia de Menandro de Efeso, en el sentido de que Hiram había destruido los templos viejos y edificado nuevos santuarios de Heracles, es decir Melqart y Astarté (Jos. Ant. lud. VIII, 5, 3; Contra App. I, 18). Al dar esa noticia de Menandro, Flavio Josefo dice en uno de los lugares (Contra App. I, 18), que Menandro aprovechó las fuentes indígenas, y,en otro (Ant. lud. VIII, 5,3 ), que él tradujo las crónicas tirias al griego ${ }^{28}$. Por eso no se pueden poner en duda las palabras de Menandro. No obstante, a primera vista esta noticia está en contradicción con el relato de Heródoto, quien dice que el templo existía desde la fundación de la ciudad. Como se ha señalado antes, esto se corresponde con los datos arqueológicos.

Hablando en general, edificar un templo no significa instituir un culto. Aún en el caso de que en Tiro antes Hiram no hubiera existido el santuario de Astarté, ello no significa que no hubiera existido el culto de esta diosa. El culto de Astarté era el más antiguo, y en el segundo milenio a. C. (o tal vez, más temprano) se extendió a gran escala, no sólo por Fenicia sino mucho más allá ${ }^{29}$. Según Filón de Biblos, quien de acuerdo con sus propias palabras, contaba el relato de Sanjunyatón, precisamente en Tiro halló Astarté la estrella que habia caído del cielo por lo que la consagró la isla (fr. II, 24). Por eso de la sola edificación del templo de Melqart por Hiram no se pueden hacer deducciones acerca de la aparición del culto del dios en Tiro.

El Melqart tirio parece un fiel reflejo del Baal ugarítico. En los mitos cuyas escenas fueron representadas en las puertas del Herakleion gaditano, aparece como la personificación del principio luminoso que lucha contra oscuros engendros de las fuerzas ctónicas ${ }^{30}$. Tal dios es relacionado con el sol ${ }^{31}$. No sin razón en la escena de la muerte de Melqart, según Silio Itálico (III, 42-44), "a un alma se la lleva hacia las estrellas una llama". Nonno (Dionys. X, 369) trata al dios tirio de Señor del fuego, que se puede ver legítimamente como la encarnación del fuego solar. Para el mismo Nonno (Dionys. 370-374) Heracles tirio se trata de Helios, el pastor

2в Cf. G. GarbinI, I Fenici. Nápoles 1980, pp. 74-78.

29 W.F. ALBRight, Archaeology and Religion of Israel. Baltimore, 1956, pp. 74-77; W.W. Baudissin, Adonis und Esmun. Leipzig, 1911, S. 17-24; W. HermanN, "Aštart", en: Mitteilungen des Instituts für Orientforschung, 5 (1969), S. 39-45; I.ScH. SCHIFMANN, Kultura drevnego Ugarita. Moscú, 1987, pp. 91-92, 154, 157-159.

so J.B. TSIRKIN, "The labour, death and resurrestion of Melqart as despicted on the gates of the Gades Herakleion", en: RSF, (1981), pp. 21-27.

31 El carácter solar de Melqart lo desmienten R. Dussau (Melqart), en: Syria, 14 (1946-1948), p. 207; y H. SEYRIG, (“Le culte du soleil en Syrie à l'époque romaine”, en: Syria, 48 (1972), p. 356) y lo defiende A. GaACIA Y BELLIDO ("Hércules Gaditanus", en: AEArq, 35), 1962, p. 73. 
de la vida humana, quien galopa por el cielo como un disco brillante, llevando en círculo el año de doce meses. Ciertamente, es difícil decir en que grado deforma Nonno la antigua leyenda fenicia dentro del espíritu del sincretismo tardoantiguo; pero el carácter solar del dios es claramente visible en la leyenda de la salvación de Gades del ataque del rey ibérico (probablemente tartésico) Ferón (Macr. Saturn. I, 20, 12). En estos mitos Melqart aparece como el dios que muere y resucita, a modo del Adonis de Biblos, del Tamuz de Mesopotamia o del Osiris de Egipto, es decir de los dioses que encarnan la vegetación que muere y resucita. Se ha conservado también el mito que relata la muerte y la resurrección del propio Melqart, sobre el que volveremos después.

Esos mitos no reflejan el carácter marítimo de Melqart y su papel como jefe de la colonización. Se puede suponer que tienen relación con el estrato mas antiguo de la mitología tiria. El templo de Gades era parecido al tirio, en arquitectura y en concepción, ya que ambos templos (y más tarde el de Tibur) han tenido un oráculo ${ }^{32}$. Es posible que, para adornar la puerta del templo, los sacerdotes gaditanos hayan utilizado un modelo tirio. $Y$, si esta suposición se confirmase, serviría de prueba complementaria de la antigüedad del santuario tirio de Melqart.

Entre tanto, el carácter marítimo del "Rey de la ciudad" se refleja en el mito de la fundación de Tiro tal como lo expone Nonno (Dionys. X, 443534). Aquí se cuenta que Heracles (Melqart) ordenó a los fundadores de la Tiro continental construir una nave, y pasando sobre las rocas Ambrosias, que erraban por el mar, y sacrificando allí, dejarlas fijas y edificar la ciudad. En calidad de modelo para construir una nave, el dios señaló el pez nautilos (navetas). De suerte que Melqart aparece ahí no sólo como el fundador (aunque indirecto) de Tiro sino también como el inventor de la construcción naval.

Aún más claro se revela el aspecto marítimo de Melqart en la relación de este dios tirio con Melicertes, una de las divinidades maritimas secundarias de la Hélade. En el mito griego se relata que Melicertes, era hijo de la mortal Ino, quien se había echado al mar junto con el niño, transformándose ambos en divinidades marítimas: Ino, en Leucótea, y Melicertes, en Palemón (Apold. III, 4, 3; Ovid. Met. IV,512-541). Antes los investigadores admitían la identificación de Melicertes con Melqart ${ }^{33}$, más tarde la

32 M.P. GARCiA Y BELLIDO, "Altares y oráculos semitas en Occidente: Melkart y Tanit", en: $R S F, 15,2$ (1987), pp. 137-139.

з3 StOLL, “Melikertes", en: ML, Bd. V, Sp. 2633-2634; F. MEYER, Melqart, en: ibid, Sp. 2652. 
recusan ${ }^{34} \mathrm{y}$ ahora, a veces, la vuelven a reconocer ${ }^{35}$. En el mundo griego Ino fue tomada por hija de Cadmo (ya en Homero Od. V, 333-334). Por otra parte, Ino es relacionada con llitía y probablemente ambos nombres tuvieron relación con una misma divinidad ${ }^{36}$. Según Estrabón $(V, 2,8)$, en la Pyrgai etrusca había un santuario muy antiguo de llitía. Las excavaciones realizadas en Pyrgai dieron fragmentos cerámicos con un nombre que deriva del de Ino. Allí mismo fueron descubiertas las célebres láminas de oro donde se ve la identificación de la Uni etrusca con Astarté ${ }^{37}$. De modo que se puede considerar, por lo menos en el Oeste, a Ino-Leucóteallitía como identificada con Uni-Astarté.

Se conoce un mito acerca del nacimiento de Melqart (Fil. fr.27). El dios supremo El, en tiempos de la guerra contra su propio hijo el Cielo, hizo prisionera a su concubina y se la dio en matrimonio a su hermano Dagón. Esta concubina estaba ya embarazada del Cielo, y poco tiempo después, nació su hijo, Demarous (fr. 18-19). A lo que parece, en la figura de Demarous se veneraba al antiguo dios semita Astar, hipóstasis masculina de Astarté ${ }^{38}$. Filón de Biblos (fr. 31) identifica a Demarous con Zeus. Cicerón (de nat.deor.), entre muchos Hércules hace mención del hijo de Júpiter y Asteria, a quien veneran sobre todo en Tiro. En la virgen estelar Asteria los investigadores ven a Astarté ${ }^{39}$. Un bajorrelieve tirio de época romana representa el alumbramiento de Melqart por Astarté ${ }^{40}$.

$\mathrm{Si}$ todas estas. reflexiones son correctas, resulta que Melqart y Melicertes son dados a luz por la misma diosa llitía-Ino-Leucótea-UniAstarté. La identificación con llitía testimonia que, en este caso a los etruscos, y quizá también a los fenicios, les interesaba aquel aspecto de la diosa que no era el de la reina de los dioses sino el de la parturienta, es decir la madre de Melqart. Deciamos que el dios marítimo de Melicertes adopta el nombre de Palemón; pero Palemón es un de los epítetos de Heracles (Hesigu. s. v. П $\alpha \lambda \alpha i ́ \mu \omega v)$. Hubo un mito que narraba el nacimiento de Palemón, de Heracles y de la viuda de Anteo (Pherécid. fr. 33e;

\footnotetext{
34 R. Dussaud, Op. cit., . 210.

35 M. Astur, Hellenosemitica. Leiden, 1967, pp. 209-211.

36 A.J. PfIFfIG, Uni-Hera-Astarte. Viena, 1965, S. 51.

${ }_{37}$ A. MAIURI, "Scavi nel santuario etrusco di Pirgi", en: Archeologia Classica, 16 (1964), pp. 49-117.

38 I. SCH. SCHIFMANN, "Otrageniye finiliyskogo kulta 'Astara y antichnoy istoriografii", en: Peredneasiatskiy sbornik. Moscú, 1986, pp. 81-82; idem. Kultura..., p. 91.

39 W.W. Baudissin, Op. cit., S. 307 ; C. Baurian, C. Bonnet, Op. cit., p. 68.

40 H. SEYrig, "Les grandes dieux de Tyre à l' époque greque et romaine", en: Syria, 40 (1963), p. 23-24, tabl. II,I.
} 
Apolod. I, 80); por lo tanto se incorpora al ciclo mítico heracleo, aunque probablemente no estaba ligado a él originariamente. Es posible que después de producirse la identificación estable de Melqart con Heracles los mitos de Melicertes se ligaban a los mitos de Heracles.

Con Melicertes se relacionaba a un delfín, que es quien recoge al niño cuando cae al mar. La estatua de Melicertes encima del delfín estaba en un templo de Istmo (Paus. II, 1, 8). El delfín había transportado a Melicertes-Palemón hasta Istmo, y en el lugar de su hallazgo por Sísipo. estaba el altar de Melicertes-Palemón (Paus. I, 44, 8; II, 1, 3). A Melicertes sobre el delfín se le representa en las monedas de Corinto ${ }^{41}$. El mismo animal marino aparece también en las monedas de Tiro, Junto con Melqart ${ }^{42}$. En la acuñación de Gades aparece también un delfín ${ }^{43}$. En Gades en tiempo de la fiesta en honor de Melqart quemaban un muñeco sobre un delfín.

De todo lo dicho se puede deducir que la saga griega de Melicertes repite, aunque probablemente de una forma muy cambiada, los cuentos tirios de la muerte y resurrección de Melqart en las olas marinas. Su apoteósis en el abismo del mar está ligada con el aspecto marítimo de su figura y culto.

¿Cuándo surgió el aspecto marítimo de Melqart?. La identificación de Melqart y Heracles aparece no más tarde del siglo $\mathrm{VI}$ a. C., y luego Melqart se identificó con algún personaje de la mitología griega ${ }^{44}$. Homero (Od. V, 333-335) menciona a la diosa Leucótea que habia sido la mortal Ino. Se puede decir que en la época homérica era conocido todo el mito, siendo incluido el relato del salto en el mar justo con Melicertes ${ }^{45}$. Melicertes estaba ligado a Beocia y a Corinto. En Beocia había reinado su padre Amafanto, y ese país fue la patria de Ino, la hija de Cadmo, el fundador de Tebas (Apolod. I, 9, 1; III, 4, 1-3). Es característico que la mitología griega haga salir a Cadmo de Tiro, y no de Sidón, que para Homero (por imitación también pasa a otros poetas antiguos) aparece como el símbolo de Fenicia en general. El hallazgo de sellos-cilindro de Mesopotamia de los siglos XIV-XIII a. C. en la Cadmea tebana confirma la presencia de

4. STOLL, Op. cit., Sp. 2634.

42 D. BARAMKI, The coins exibuted in the Archaelogical Museum of the American University of Beirut. Beirut, 1968, p. 25; D. HaRdEN, Op. cit., p. 157, plate 10 d-e; S. MoscatI, I Fenici e Cartago. Torino, 1972, pp. 460-461.

43 A. Vives Y ESCUdero, La moneda hispánica. Madrid, 1924, t. 2, pp. 52-53; t. 3, p. 8.

44 R. Dussaud, Op. cit., pp. 216-222.

45 LESkY, "Melikertes", en: RE, Hbd. 21, Sp. 517-518. 
contactos de Tebas con el Oriente en la época micénica ${ }^{46}$. Esa fue la época de las relaciones entre Grecia y Fenicia en las esferas de la lengua y de la literatura ${ }^{47}$. Sólo en la época micénica pudo nacer Tyros del nombre semita Sor $^{48}$.

Otro centro del culto de Melicertes fue Istmo. Hasta aquí llevó a Melicertes el delfín, y aquí fueron organizados los Juegos Istmios en honor de Melicertes (Apolod. III, 4, 3; Paus. I, 44, 8; II, 1, 3), que administraban los corintios. Otro "Señor» de los Juegos fue Poseidón ${ }^{49}$. Esto es completamente natural, pues Poseidón pertenece al grupo de las divinidades olímpicas. Más difícil es comprender el papel de Melicertes. Es difícil imaginarse que unos juegos tan célebres (aunque llegaron a ser panhelénicos sólo bajo los Cipsélidas) ${ }^{50}$ fueron consagrados a un dios tan secundario como Melicertes-Palemón. Cabe suponer que, durante cierto tiempo, Melicertes jugara allí un papel más importante que en el primer milenio a. C. y tal vez, cuando después de la invasión dórica, Poseidón llegó a ser el dios del mar - lo que no era en la época micénica- ${ }^{51}$, se le uniera a Melicertes en calidad de "señor" de los Juegos. Si Ino fue realmente ligada a llitía (o fue una de sus hipóstasis), hay que recordar que llitía era integrante del Panteón Micénico ${ }^{52}$.

Todo conduce a la idea de que el culto de Melicertes se originó en la Grecia micénica, asumiendo el aspecto marítimo de Melqart, tal y como se refleja en los mitos de Melicertes e Ino, existió ya en la mitad del segundo milenio a. C. Esto también confirma la creencia de los sacerdotes tirios de la antigüedad de su templo. De modo que es verosímil la creación de los templos de Melqart en Tasos, Gades y Lixus finales del segundo milenio a. C.

La contradicción entre Heródoto y Menandro al vez pueda resolverla Heródoto mismo. El historiador dice que en Tiro hay también otro templo de Heracles de Tasos. Por lo visto, Heracles de Tasos es la hipóstasis de Melqart venerada en Tasos. Lo de que algunas deidades fenicias podían

46 G. BUNNENS, Op. cit., p. 19.

47 P.A. Grinzer, «Dve epoji literaturnyj svyasey", en: Tipólogiya i vzaimosvyasi literatur dreunego mira. Moscú, 1971, pp. 12-45.

${ }_{48}$ I. SCH. SCHIFMANN, Vozniknoveniye..., pp. 13-14.

49 O.W. ReINmuth, "Istmien", en: Kleine Pauly, 2 (1979), Sp. 1474-1475; G. Tomson, Op. cit., S. 213.

so O.W. ReINMUTH, Op. cit., Sp. 1474.

5t A.BARTONEK, Zlatoobilniye Mikeny. Moscú, 1991, p. 200.

52 ibid., p. 206; L. Press, Zicie codzienne na Krecie w panstwie króla Minosa. Varsovia, 1972, p. 163. 
tener hipóstasis, se confirma por el ejemplo de Astarté cuya hipóstasis siciliota fue Astarté Ericinia (Aten. IX, 51, 394 f; Diod. IV, 83, 4; El. Var. Hist I, 15) ${ }^{53}$. Por eso es posible que el templo edificado por Hiram en Tiro fuera del Melqart de Tasos, al cual honraban los tirios, como los cartagineses, a Astarté Ericinia. Por otra parte, existe la opinión de que el texto de Menandro pudo ser interpretado como el indicio de la construcción por Hiram del santuario conjunto de Melqart y Astarté ${ }^{54}$. En este caso sería un templo distinto del herodoteo.

Más difícil es resolver el problema de la fiesta de la resurrección de Melqart establecida por Hiram (Jos. Ant.lud. VIII, 5, 3; Contra App. I, 18). La muerte y resurrección de Melqart pertenecen al nivel profundo de la mitología de este dios y reflejan su carácter agrario, que precede al carácter marino. Sin embargo, hay que observar que los inicios del culto de un dios y de la fiesta en su honor no siempre son simultáneos. Por ejemplo, Dionisio fue un dios adorado ya en la época micénica ${ }^{55}$ pero la celebración de las Grandes Dionisiacas no fue establecida en Atenas hasta Pisistrato ${ }^{56}$. Veamos los personajes del mito de Melqart (Aten. IX, 47, 392 f). El asesino de Melqart fue Tifón, y su resucitador, Yolao. Tifón es el dios fenicio Mot o Yam (más probablemente el último) ${ }^{57}$.

Más interesante es la figura de Yolao. Según el mito (Diod. IV, 29-30), Yolao era el jefe de la flota de su tío Heracles en la época de la colonización de Cerdeña que actúo después en esta isla por su propia cuenta. Los indígenas, según Diodoro, sacrificaban al dios Yolao y lo llamaban pater, de modo que el Yolao sardo era un dios con el título de paterSardus-Pater. Entre las inscripciones votivas del templo de Sid excavado en Antas hay una bilingüe donde el nombre latino Sardi corresponde el fenicio $/ s d^{58}$. De aquí se puede deducir que el Yolao de los autores griegos es el Sid fenicio. Sid es también el dios sanador ${ }^{59}$, de modo que su papel en el destino de Melqart aparece claro.

53 M. Leglay, Saturne Africaine. París, 1966, p. 354; S. Moscatı, "Sulla diffusione del culto di Astarta Ericinia”, en: Oriens Antiquus, 7 (1968), pp. 91-94.

54 G. GARBINI, Op. cit., p. 75, n. 5.

55 A. Bartonek, Op. cit., p. 205; S. YA. LuRYE, Yazyk i kultura Miikenskoy Grecii. MoscúLeningrado, 1957, pp. 291-292.

56 A. ANDREWS, "The Tyranny of Pisistratus", en: $C A H, 3,3$ p. 412.

57 B. ZANNINI, "L'interpretatio graeca dell'ugaritico Yam", en: Atti del II Congreso internazionale di studi fenici e puniche. Roma, 1991, pp. 431-437; I. Sch. SCHIFMANN, Kultura..., p. 156.

58 J. FERRON, "Lenature de dieu Sid d"après les decouvertes rècentes d'Antas", en: Études sémitiques. París, 1975, p. 12.

59 Ibid., pp. 9-15; F. BARRECA, “La colonizzazione fenicio-punica in Sardegna alla luce delle nuove scoperte", en: Simposio de colonizaciones. Barcelona, 1974, pp. 9-11; G. GARBINI, "Le iscrizioni puniche de Antas (Sardegna)", en: Annali, 29 (1969), p. 318-321. 
El descubrimiento de este dios ha replanteado la cuestión sobre la denominación «fenicios/sidonios", sobre la mención de Sidón como el primogénito de Canaán y sobre el nombre de esta ciudad, cuyo epónimo pudo ser Sid ${ }^{60}$. Malalas (Chron. III, 69) conservó una noticia interesante que puede remontarse a las fuentes fenicias, aunque desfigurada ${ }^{61}$ : un tal Sid hijo de Egipto, fue en época de Abrahán, el fundador de Sidón. La acentuación del papel de Sid como el salvador de Melqart y, por otra parte, como su compañero y tal vez hijo ${ }^{62}$, parece reflejar unas relaciones complicadas entre Tiro y Sidón.

Asi, pues, no hay razón para afirmar la ausencia del culto de Melqart en el segundo milenio a. C., y en virtud de tal ausencia, desmentir la tradición de los templos que llevaba los inicios de la colonización fenicia hasta esa época tan remota.

Es necesario observar que los templos de Melqart no fueron los únicos que fundaron los fenicios en las tierras de ultramar. En Citera fue el templo de Astarté, y según Plinio (XVI, 216), simultáneamente con Utica fue fundado el templo de Apolo. Los investigadores identifican generalmente a Apolo con Reshef ${ }^{63}$. La promoción de Reshef en vez de Melqart parece explicarse por las condiciones particulares de la fundación de Utica, donde conforme a la sentencia de los tirios, fue enviada la juventud (Ins. XVIII, 4, 2). Reshef, el dios guerrero ${ }^{64}$ concuerda enteramente con el papel de protector divino de un sector inquieto y dinámico de la población como lo es la juventud.

Otro grupo de informaciones sobre la etapa inicial de la colonización son las noticias en las que un templo, o bien no es mencionado de ninguna manera, o bien se menciona sólo de paso como algo conocido. Sobre el templo guardan silencio los melios. Por causa del comercio, como dice Tucídides (VI, 2,6), se establecieron los fenicios en Sicilia y en los islotes cercanos. Diodoro (V, 20, 1-2) escribe que los fenicios con la esperanza de obtener grandes riquezas, se dirigieron al Océano y fundaron en el litoral europeo Gades, entre otros el templo magnífico de Heracles. Pasa

60 J. FerRon, Op. cit, pp. 14-15; idem, “Sid: état actuel des connaissances", en: Le Museon, 89 (1976), p. 440; 1. SCH. SCHIFMANN, "Finikiyskaya istoricheskaya tradiciya $\vee$ grecheskoy i rimskoy istoriografii", en: Dreveni y Vostok i mirovaya kultura. Moscú, 1981, p. 104, n. 2.

61 S. RIBICHINI, "Una tradizione sul fenicio Sid", en: RSF, 10,2 (1982), p. 174.

62 C. BONNET, "L'onomastique de Melqart", en: RSF, 17,1 (1989, p. 34.

63 W.F. Albright, Op. cit., p. 91; M.K. Schatter, Alter Orient und Hellas. Insbruck, 1974, S. 173; F.W. Walbanc, A historical Commentary on Polybius, t. II, Oxford, 1959, p. 47.

64 W.F. Albright, Op. cit., p. 91; D. ConRAD, "Der Gott Reschef", en: Zeitschrift für die Alttestamentische Wissenschaft, 83 (1971), S. 180-182; A. GARCiA Y BelLIDO, "Les religions...", p. II. 
completamente en silencio el templo Veleyo Patérculo, cuando habla de la fundación de Gades y de Utica por la flota tiria, que por entonces era la más fuerte del mundo. Fecha tal fundación ochenta años más tarde que Mela, quien relata la fundación del templo. El Pseudo-Aristóteles menciona sólo la construcción de la ciudad, no la del templo. Hablando de la fundación de Utica, el Pseudo-Aristóteles cita unas "Historias fenicias". Puesto que el tiempo de la fundación se cuenta a partir de la fecha de la fundación de Cartago se puede admitir que esas "Historias" eran obras de historiadores cartagineses; es posible que se tratara de una de las "Historias púnicas" mencionadas por Servio (Ad Aen. I, 343; 378). Sabido es que en Cartago existió una vasta literatura que se hallaba en bibliotecas que luego pasaron a reyes africanos (Plin. XVIII, 22) ${ }^{65}$. De uno de esos reyes, del rey númida Hiempsalo, conoció Salustio las noticias sobre la historia temprana de Africa y la historia de la colonización fenicia, incluida su prehistoria mítica.

Es bastante difícil establecer las fuentes de Veleyo Patérculo. Una de ellas fue probablemente Nepote ${ }^{66}$. Por otra parte, Nepote conoció sin duda las obras de Sósilo y Sileno, compañeros de Aníbal (Nep. Han. 13). De estos autores pudo sacar Paterculo su propia tradición fenicia. Esta última idea se confirma por otras consideraciones. Estrabón (XVI, 2, 22) observa que, aunque los poetas claman más por Sidón, y Homero ni siquiera menciona a Tiro, las colonias enviadas a Libia e lberia, e incluso al otro lado de las Columnas celebran más a Tiro. La colonia del otro lado de las Columnas es sin duda Gades. Es difícil saber a qué colonias de Libia e Iberia se refiere el autor, pero entre ellas pudieron encontrarse tanto Utica como Cartago. La celebración de Tiro aparece en las palabras de Patérculo, quien glorifica el poder marítimo de los tirios.

Estrabón mismo menciona más de una vez las navegaciones fenicias más antiguas del Extremo Occidente y la fundación alli de ciudades, poco después de la guerra de Troya $(1,3,2)$. En estos casos nada dice el geógrafo sobre los templos u oráculos, lo que hace pensar que utilizaba una variante de la tradición distinta de la del relato sobre la fundación de Gades. Puesto que en estos casos se trata de la fundación de ciudades, esta variante de la tradición se podría denominar «urbana».

La tradición «urbana" parece opuesta a la "de templo», dando, a veces fechas diferentes. Por ejemplo, la tradición «de templo» atribuye la fundación

65 W. Huss, Op. cit., S. 362-363.

66 M. von ALBRECHT, Geschichte der römischen Literatur. Bern, 1992, S. 843 (cf. S. 383). 
del templo de Gades a la época de la guerra de Troya, es decir, según las fechas tradicionales, hacia el 1184 a. C., mientras que la "urbana" se refiere al año octogésimo después de la caída de Troya, ¿significa esto que el templo ha surgido realmente algunas décadas antes que la ciudad?. En principio es posible. Los templos pudieron ser bases de apoyo y puntos de referencia en el comercio marítimo, ellos daban una garantía de la protección divina, y, por tanto, una seguridad, aunque fuera ilusoria, a los mercaderes que llegaban ${ }^{67}$. Es posible que en Tasos no hubiera núcleo urbano propiamente dicho, y que el propio templo explotara las minas de oro de la isla. Sin embargo, Estrabón, (III, 5, 5) simultanea la fundación de la ciudad y del templo. La misma impresión causan las palabras de Diodoro $(V, 20,1)$. Se puede replicar que los fenicios vinieron muchas veces a Hispania, pero Estrabón reúne todo en tres viajes. No obstante, despierta dudas la fecha de Mela.

Ante todo, esta fecha se opone a las restantes fechas tratadas antes. En lo que respecta a la metrópolis, estaba la tradición que atribuía la fundación de Tiro a los sidonios, quienes habrían escapado después de la destrucción de los ascalonitas, un año antes de la guerra de Troya (Just. XVIII, 3, 5) es decir en el 1195 a. C. Flavio Josefo (Ant. lud. VIII, 3, I) confirma esta tradición: Tiro fue fundada doscientos cuarenta años antes de la construcción del templo en Jerusalén por Salomón. Puesto que el templo fue construido en el año undécimo del reinado de Salomón (I Reg. VI, 1), si fechamos ese reinado en el 965 al 928 a. C. ${ }^{68}$, la fecha de la fundación de Tiro es el 1194 a. C. y si se aceptan otras fechas de los inicios del reinado de Salomón ${ }^{69}$, tendremos, en cualquier caso el periodo comprendido entre el 1200 y el 1114 a. C. Aunque Tiro existiera mucho tiempo antes, la coincidencia de las fechas no puede ser casual: probablemente ocurrió entonces un hecho importante en la historia de Tiro que permitió atribuir la fundación de la ciudad a esa época.

Se puede citar un ejemplo análogo. Tenemos dos fechas de la fundación de Massalia por los foceos. Una la atribuye al tránsito entre de los siglos VII y VI a. C., o los inicios del siglo VI a. C. (Arist. apud Harpocr., FHG II, fr. 238; Just. XLIII, 3. 4 4, 12; Liv. V, 34, 78; Ps. Scymn. 211-214;

67 W. Culıcan, «Phoenicia and Phoeniciana», en: $C A H, I I 1,2$ (1991), p. 488; G. BUnNens, Op. cit., pp. 282-285; M. Gras, P. ROUILLARD, J. TEIXIDOR, Op. cit., pp. 108-109.

68 E. BICKERMAN, Jronologia drevnego mira. Moscú, 1976, p. 192; H. TADMOR, "Die Zeit des Erstes Tempels, die babylonische Gefangenschaft und die Restauration", en: Geschichte des jüdischen Volkes, Bd. I. Munich, 1981, S. 128.

69 A. van den Branden, Op. cit., p. 171; O. EIssfeldt, “Tyros", en: RE, Hbd. 14A, Sp. 1883; P. CINTAS, Manuel d'archéologie punique, t. I. Paris, 1970, p. 116, n. 445. 
Euseb. Chron. 92-93 Schoene); otras a mediados o inicios de la segunda mitad del siglo $\mathrm{VI}$ a. C., entendiendo que los foceos escapaban del rey persa (Isócr. Archid 84; Paus. X, 8, 6; Sén. ad Helv. VII, 8; Gel. X, 16, 4; Am. Marc. XV, 9, 7). Esta última tradición parece más difundida en la Grecia Balcánica. Con todo, ahora está probado que la variante de Aristóteles, Trogo y Timeo es la única correcta. La aparición de la otra variante hay que ligarla a la lucha política desarrollada en Massalia, con la aspiración de los foceos que habian emigrado a Occidente dos generaciones después de los primeros colonos y se habían encontrado con ciudadanos de segunda clase. Por eso, estos segundos colonos intentaban demostrar que ellos eran los auténticos fundadores de la ciudad, no los primeros. La causa de la difusión de la variante es clara: la deducción de colonias en aquella época era habitual, pero la fuga de los foceos, que prefirieron la emigración a la sujeción al rey persa aparecía como un acto glorioso y grande ${ }^{70}$.

Por lo visto, también en Tiro la aparición de la tradición que la hacía fundada por los sidonios hay que ligarla a la inmigración de los sidonios y su aspiración a colocarse por lo menos al mismo nivel que el viejo colectivo civil de Tiro. Pero esto debe exigir un tiempo considerable, de modo que es difícil imaginarse que los tirios después de diez años pudieran ya fundar el templo de su dios en el extremo occidente del mundo de entonces. Sin embargo, es curioso que el templo insistiera tanto en su antigüedad, en contraposición a la tradición «urbana».

Estas fechas turban a los investigadores actuales por su dependencia de la guerra de Troya, y, en general, por la clara helenización de toda la historia, que sirve de base importante para la duda sobre la autenticidad de toda tradición de la fundación tan temprana de Gades, Utica y otros poblamientos fenicios. Surge la sospecha de que toda esta tradición tenga un origen único, y de que tal vez su fuente sean los escritores alejandrinos, que, recordando el papel que jugaban los fenicios en Homero, ligaran artificialmente los mitos de la guerra de Troya y de los Heráclidas con los viajes de los fenicios ${ }^{71}$. Parece poco probable que tal punto de vista sea correcto. Ya Estrabón distinguía a Homero, que pasa en silencio a los tirios, y a los fenicios que cantan a los tirios. $Y$, aunque el propio Estrabón llama a veces $(I, 2,35)$ a los colonos fenicios del Océano "sidonios" (sólo refiriéndose a opiniones de otros escritores), y así también Salustio (Jug. 78,1), cuando se trata de la metrópoli de los colonos, se menciona sólo Tiro.

70 Ju. B. TSIRKIN, “Aristotel i osnovaniye Massalii», en: Antichnyi mir i arjeologiya, 8, Saratov, 1990, pp. 11-21.

"S. Moscati, Tra Tíro e Cadice. Roma, 1989, p. 13. 
Es imposible atribuir los mitos de Heracles a los fenicios. Más bien al contrario: aún siendo un héroe típicamente griego, Heracles asumió también rasgos orientales ${ }^{72}$. Según Diodoro (IV, 17-18), al realizar su décima hazaña Heracles estaba al frente no sólo de un gran ejército sino también de la marina. La leyenda paralela, que se remonta al menos a Estesícoro y expone la versión antiquísima y precisamente griega de esta marcha, presenta a Heracles como héroe "de tierra»: no en vano para pasar a Eritia, Heracles amenazándolo con su arco, quitó a Helio la copa de oro ${ }^{73}$. Este dato, y el itinerario mismo de la marcha de Heracles, que coincide con las regiones de la colonización fenicia en su etapa primera, así como la presencia del gran ejército, que hay que poner en relación con el ejército de Hércules-Melqart en tiempo de su marcha a Hispania (Sal. Jug. 18), todo ello conduce a la idea de que la base del mito narrado por Diodoro es fenicio, y que después fue helenizado e incluido en el ciclo mítico sobre Heracles ${ }^{74}$.

Naturalmente no hay que desmentir la helenización de la tradición fenicia. Sin embargo en la época del helenismo, aspirando a incluir su historia en el torrente histórico general muchos bárbaros creaban sus obras en griego. Por eso se explica la aparición de los trabajos de Manetón y Bero, la creación de las Septuaginta ${ }^{75}$. Los judíos, a pesar de su tendencia a diferenciarse de los paganos insistían en su parentesco con los espartanos (I Mac. 12, 6-7; 21). Por su parte los griegos se interesaban por las historias de pueblos y estados indígenas y usaban sus tradiciones para sus propias elaboraciones. Esto fue lo que hizo en la época romana Filón de Biblos, quien utilizó, para el libro primero de su "Historia fenicia» la obra teológica antigua de Sanjunyatón, aunque la transformó dentro del espíritu evemerista. Este autor aspiraba a aproximar en los posible las deidades fenicias a las griegas, frecuentemente identificándolas. Las crónicas tirias fueron presentadas en griego por Menandro y Dión. El propio Menandro señala la llegada de Menelao a Fenicia después de la caída de Troya (Clem. Alex. Strom. I, p. 140, 8).

La inclusión en el torrente histórico global, cuya parte esencial era la historia de la Hélade y de Roma, ocasionó también la recepción del esquema histórico, cuyo jalón mas importante era la guerra de Troya. Por

72 W. PÖtSCHER, «Herakles", en: Kleine Pauly, 2, Sp. 1051.

73 N.A. Chistayakova, "Drevnyaya poeziya grecheskogo Zapada", en: VDI, 1980, 4, pp. 41-43.

74 M.N. MAKUSHKIN, "Mif o Gerakle kak istochnik po istorii Severo-Zapadnoy Sicilii", en: Nercia, 2 (1978), pp. 8-10.

75 I.Sch. SCHIfManN, Vetijy Zaven i ego mir. Moscú, 1987, p. 14. 
eso no es sorprendente que, al modo de los autores grecorromanos, los escritores orientales aceptaran este esquema cronológico.

En el Occidente la helenización de las tradiciones locales pudo tener lugar más temprano. En Cartago la helenización de la cultura se produce en los inicios del siglo IV a. C. En este curso pudieron actuar también los sacerdotes gaditanos. Aunque en su templo existiese alguna desconfianza hacia los extranjeros, como se ve en las palabras de Euctemón ( $A v$. or. mar 358-363), cuando narra que orando éstos en el templo, fueron obligados a abandonarlo lo más pronto posible, ante la presencia de navegantes extranjeros para evitar su contacto. La desconfianza más grande de los judíos no impedía, como vimos, presentarse como los hermanos de los espartanos. De modo que los autores griegos y romanos pudieron recibir la referencia a la guerra de Troya de los mismos fenicios. Además, hay que acentuar que la fecha de la fundación de Gades y Utica ligada con la guerra de Troya es confirmada por las fechas del Pseudo Aristóteles y de Plinio, que no tienen ninguno referencia a esta guerra.

Asi, pues, no hay motivos para dudar de la autenticidad de la tradición que atribuye la etapa primera de la colonización fenicia de los finales del siglo XII y los inicios del siglo XI a. C.

Pasemos ahora a la metrópoli. A pesar de la opinión de Moscati ${ }^{76}$ en Fenicia no ha tenido lugar ninguna censura en el desarrollo histórico hacia el 1200 a. C. Las destrucciones catastróficas ligadas con movimientos étnicos de esta época no han tocado directamente Fenicia. Etnica, política, social y culturalmente la historia de Fenicia de finales del segundo milenio a. C. y del primer milenio a. C. es la continuación directa de la época anterior ${ }^{77}$. Naturalmente los acontecimientos violentos de ese tiempo no pudieron ser evitados por completo en Fenicia. Los filisteos de Ascalón destruyeron Sidón, cuyos habitantes emigraron a Tiro; como resultado, se produjo en el país una presión demográfica. Si se está de acuerdo en que el sacrificio mlk es la respuesta a tal presión, hay que tener en cuenta que van apareciendo testimonios de este sacrificio en los siglos XII-X a. $\mathrm{C}^{78}$.

\footnotetext{
76 S. Moscati, Tra tiro e Cadice, pp. 19-24; idem, "Gl'inizi dell'eta fenicia", en: Rendiconti dell'accademia nazionale dei Lincei, ser. IX, v. IV,I (1993), p. 15.

77 R. DE VAuX, "Le Phénicie et les Peuples de la Mer", en: Mélanges de I'Université Saint-Joseph. 45 (1969), pp. 48-491, 498; H. MülLER-KARPE, "Früe Städte in der Alten und Neuen Welt", en: Jahrouch des RGZM, 36,1 (1989), S. 19; R. STIEGLITZ, Op. cit., pp. 9-11; W. RớlıG, “Die Phönizier des Mutterlandes zur Zeit der Kolonisierung", en: Phönizier im Westen. Mainz, 1982, S. 16; O. NEGBI, "Early Phoenician Presence in the Mediterranean Islands", en: AJA, 96 (1992), pp. 601-603.

${ }_{78}$ C.G. WAGNER, "El sacrificio del Moloch en Fenicia: una respuesta cultura adaptiva a la presión demográfica", en: Atti de // Congreso Internazionale di Studi Fenici e Puniche, Rome. 1991, pp. 411-416. Cl. O. NEgBl, “Early Phoenician Presence...", p. 611.
} 
Por entonces solucionar tal presión con una expansión cerca del territorio propio era impensable, ya que el país más útil para la expansión hacia el sur y sureste, Palestina, era entonces el campo de la rivalidad encarnizada entre hebreos y filisteos, y, junto a los límites meridionales de Fenicia) se habian establecido los tjequeros. El camino hacia el este tenía como barreras los montes del Líbano y el Antilíbano, fácilmente penetrables para el comercio o las expediciones militares, pero muy difíciles para las migraciones masivas. Además, en Siria aparecen ya entonces los arameos, que pueblan ese país ${ }^{79}$. La única salida era la salida hacia ultramar.

Por ese tiempo los fenicios eran conocidos en el Mediterráneo. Los hallazgos de la figura de bronce de un dios fenicio de los siglos XIV-XII a. C., cerca de las costas de Sicilia; el cilindro-sello sirio del siglo XIV a. C., los restos de huevos de avestruz, los ídolos de hueso de hipopótamo y los peines de marfil de finales del segundo milenio a. C. encontrados en Hispania; los escarabeos egipcios anteriores al 1200 a. C. de Utica y Lixus, todo eso lo testimonia ${ }^{80}$. Diodoro $(V, 35,4)$ dice, sobre las navegaciones de los fenicios para adquirir la plata, que vendían después en Grecia, Asia y otros paises, y obtenian grandes ganancias. En relación con esto relata Diodoro la anécdota de que los fenicios cortaron las anclas de sus barcos y las sustituyeron por plata. La misma anécdota se repite en el Pseudo-Aristóteles (de mir. ausc. 135). Y solamente después de estas navegaciones con las que se enriquecieron, emprendieron los fenicios la construcción de las colonias (Diod. V, 35, 5). Todo aboga en favor de una fase de precolonización ${ }^{81}$.

En esta etapa Tiro ha jugado un papel importante. Mientras que Biblos fue el eslabón principal de las relaciones con Egipto, Tiro (tal vez junto a Ugarit) tomaba parte activa en el establecimiento de los contactos

79 H. KLENGEL, Geschichte und Kultur Ahsyriens, Leipzing, 1919, pp. 165.

so J.M. BLÁzQUEZ, Tartesos y los origenes de la colonización fenicia. Salamanca, 1975, pp. 2326; P. Cintas, Op. cit., pp. 271-274, 307-308; A. Montenegro Duque, historia de España antigua, T. I. Madrid, 1972, p. 308; A. PaRfot, M. ChÉhab, S. Moscatı, Op. cit., p. 202; P. Schauef, “Orient in spätbronze - und früheisenzeitlichen Occident”, en: Jahrbuch des RGZM, 30 (1983), S. 177-183.

\&1 En relación de la colonización griega la noción de precolonización fue presentada en años 30 (A. BLACKEWAY, "Prolegomena to the Study of Greek Commerce with Italy, Sicily and France in the eight and seventh centuries B.C.", en: ABSA, 33 (1932-1933), pp. 170-208, y fue aceptada por muchos investigadores de la colonización griega (por ejemplo: G. VALLET, Rhegion et Zankle. Paris, 1958, pp. 57-58; K.M. KolobovA, Iz istorii rannegrecheskogo obscestva. Leningrado 1951, pp. 152-153). La presencia de la precolonización fenicia fue mostrada por S. Moscati (S. MOSCATI, "Precolonizzazione greca e precolonizzazione fenicia", en: RSF, II,I (1983), pp. 1-7. Apoyáronle también otros eruditos (por ejemplo: C.G. WAGNER, “Fenicios y cartagineses...", pp. 9-14, 18-22). Estamos de acuerdo con esta idea pero atribuimos la precolonización fenicia a tiempos anteriores a los siglos XII-XI a. C. 
occidentales ${ }^{82}$. No sin razón en la tradición griega se atribuye insistentemente al tirio Cadmo la fundación de Tebas. Curcio Rufo (IV, 4, 20) llama incluso a Tebas colonia tiria, a la par de Gades y Cartago.

La colonización fenicia fue en realidad la empresa tiria. Esto, en todo y por todo, tiene relación también con su etapa primera. Parece que la promoción de Tiro estaba condicionada por varios factores. Primeramente la participación activa en el comercio occidental, que Tiro era en el segundo milenio a. C. el centro marítimo y tenía un puerto verdaderamente importante, lo tetismonia la carta del rey tirio al rey ugarítico ${ }^{83}$. En segundo lugar, precisamente Tiro recibió a los fugitivos de la Sidón destruida, lo que llevó a un fuerte incremento de la población y a una elevada presión demográfica, provocando tal vez la lucha interna, de la que habian sido eco la leyenda sobre la fundación de Tiro por los sidonios. Hay que tener presente también la amenaza asiria. Como resultado de la campaña de Tiglatpileser I, Biblos, Sidón y Arvad pagaban tributo al rey asirio (ANET, p. 275). Aunque Fenicia no cayese inmediatamente bajo el poder asirio, la amenaza era muy grande ${ }^{84}$ y no se podia desdeñar. Recordemos que mucho más tarde, Isaya propondría a los tirios amenazados por los asirios la emigración ultramarina. No es necesario sobreestimar el miedo frente a los asirios, pero la coincidencia de las fechas del reinado de Tiglatpilser I (1115-1077 a. C.) y de la primera etapa de la colonización fenicia, así como la mención de Tiro entre los tributarios del rey, hacen suponer un vínculo entre estos fenómenos.

La emigración a los países lejanos fue utilizada para adquirir ganancias económicas considerables. Tucídides (VI, 2,6), Diodoro $(V, 20 ; 35,4)$ y el Pseudo-Aristóteles (de mir ausc. 135) acentúan el carácter comercial de las acciones fenicias. Sus objetivos más importantes eran los metales nobles. No en vano los caminos de la colonización se apoyaban en Tasos y el sur de Hispania. El objetivo principal de los puntos intermedios quizá fuera garantizar estos caminos, pero probablemente también jugaban un papel en el comercio, abasteciendo, aunque en cantidades menores, de plata y de oro, y aparte de eso, de conchas, de púrpuras y de cereales ${ }^{85}$. A cambio los fenicios daban aceite, bibelotos y ' $\alpha \vartheta v$ p $\mu \alpha \tau \alpha$ (Diod. V, 35).

82 H.J. Katzenstein, Op. cit., p. 27.

83 EL LIPINSKI, “Recherches ugaritiques", en: Syria, 44 (1967), pp. 283-284; C. BAURAIN, C. BONNET, Op. cit., pp. 63-64.

${ }_{84}$ Istoriya drevnego Vostoka, t. I,2. Moscú. 1988, p. 109.

85 A.L. HUXLY, "The History and Topography of Ancient Kythera", en: Kythera. Londres 1972, pp. 36-37; O. MeLtzer, Geschichte der Karthager, Bd. I., Berlin. 1870, S. 86-89, 448-450. 
'A $\vartheta$ v $\rho \mu \alpha \tau \alpha$ son tal vez tejidos estampados, amuletos, artículos utilitarios y cosas por el estilo ${ }^{86}$. Ese es el típico comercio colonial, que establecerían los cartagineses muchos siglos después en las costas africanas (Her. IV, 196), y más de dos milenios después los ingleses en la misma Africa. Semejante comercio no exige un nivel alto de desarrollo en los comerciantes indígenas y puede reducirse al "cambio mudo", como lo realizaban los mismos cartagineses.

A veces los fenicios pudieron explotar ellos mismos las minas. Así ocurrió en Tasos. Hablando sobre esto Heródoto (VI, 47) usa la palabra $\mu \tau \imath \vartheta \alpha \nu \tau \varepsilon \varsigma$ (participio de $\kappa \tau \iota \zeta \imath v)$. Siempre usa este verbo cuando se refiere a la fundación de una ciudad o primer establecimiento en cualquier área (por ejemplo, I, 16; II, 99; IV, 144). Por eso se puede decir que también en este caso para Heródoto los fenicios fueron fundadores de las minas tasias.

Los fenicios fundaban simples puntos de apoyo, factorías sin población estable y estaciones de ancla. Tucídides (VI, 2,6) confirma en relación con el comercio de los fenicios, su establecimiento en Sicilia y en los islotes cercanos. La utilización por el historiador del verbo oìkéw (en imperfecto ڤँкоиv) testimonia, que no se trata de puertos de comercio provisionales, sino de colonias estables con población constante. En grado aún mayor tiene esa relación con ciudades como Gades y Utica. Refiriéndose a la fundación de Utica, Justino (XVIII, 4, 2) señala dos causas: el exceso de habitantes en Tiro y la necesidad de enviar a la juventud a una colonia. Un envío de los elementos excedentes e inquietos sería inútil, si se tratase de factoria provisional, cuyos habitantes debieran volver. Las tentativas repetidas de fundar Gades (Estrabón III, 5,5) deben de testimoniar las relaciones complicadas con los indígenas ${ }^{87}$. De suerte que la ciudad sólo pudo existir como punto estable. De esto da testimonio también su nombre Gadir ("fortificación", "lugar cerrado").

En el siglo XI a. C. la expansión ultramarina de Tiro se agotó. A eso contribuyen circunstancias varias. Hacia ese tiempo los fenicios establecieron contactos directos con las fuentes de oro y de plata y con la red de puntos que unía esas fuentes y la metrópoli. El resultado es que fueron logrados los objetivos económicos de la colonización. En el Oriente ocurrie-

86 A. Parfot, M. Chéhab, S. Moscati, Op. cit., p. 147; J.M. Bläzquez, Tartessos..., pp. 44-45.

87 I. SCH. SChIfMAnN, "Vozniknoveniye...", pp. 24-25; A. Schulten, Tartessos. Hamburgo, 1950, S. 34-35. Según C.G. WAGNER, tres tentativas de fundar Gades se ligan con las navegaciones esporádicas, precoloniales de los fenicios: «Fenicios y cartagineses...", p. 20. 
ron cambios importantes. Después de Tiglatpileser I, los reyes asirios no emprendían expediciones más allá del Eúfrates, y luego, pronto Asiria decayó profundamente ${ }^{88}$, de modo que sólo dos siglos después sintieron de nuevo los fenicios la amenaza asiria. Decayeron también otros grandes estados del Próximo Oriente. Mayor papel todavia han jugado los cambios ocurridos cerca de la frontera meridional de Fenicia. Los filisteos iban estando más abiertos, y en algunos establecimientos filisteos hay huellas de la coexistencia pacífica entre filisteos y fenicios. Los tjekeros, que poco antes amenazaban al rey de Biblos, ahora estaban muy debilitados, y eso 10 aprovecharon los fenicios. Las excavaciones mostraron en sus poblaciones, entre ellas su capital Dor, un claro nivel de destrucciones, y encima de ese nivel aparecen los fenicios, lo que atestigua la conquista de las ciudades tjekeras por éstos ${ }^{89}$. En una palabra, los fenicios (precisamente los tirios) habían encontrado posibilidades de resolver sus problemas demográficos cerca de su patria.

Asi pues, se destaca una primera etapa, netamente marcada en el tiempo y espacio, de la colonización fenicia en el Mediterráneo. Aproximadamente dos siglos la separan de la siguiente.

P. S. El Dr. A. N. Sceglov da a conocer en un informe verbal que las noticias de Estrabón (VII, 4, 2) sobre el antiguo Quersoneso, que todos los arqueólogos recusaban, ahora se han confirmado enteramente. Eso refuerza la confianza en los autores antiguos, incluso cuando no existen pruebas arqueológicas.

88 Istoriya drevnego Vostoka, p. 110.

89 E. STERN, "New Evidence from Dor for the First Appearance of the Phoenicians Along the Northern Coust of Israel", en: BASOR, 279 (1990), pp. 30-32. 